\title{
19-year audit of benign jaw tumours and tumour-like lesions in a teaching hospital in Nairobi, Kenya
}

\author{
Fawzia M. Afrid Butt ${ }^{{ }^{*}}$, Julius Ogengo ${ }^{1}$, Jyoti Bahra ${ }^{2}$, Mark L. Chindia ${ }^{3}$, Elizabeth A. O. Dimba ${ }^{4}$, \\ Evelyn Wagaiyu ${ }^{5}$ \\ ${ }^{1}$ Human Anatomy University of Nairobi, Nairobi, Kenya \\ ${ }^{2}$ Dental Surgeon, Nairobi, Kenya \\ ${ }^{3}$ Department of Oral \& Maxillofacial Surgery, University of Nairobi, Nairobi, Kenya \\ ${ }^{4}$ Department of Oral \& Maxillofacial Surgery, Oral Pathology \& Medicine, University of Nairobi, Nairobi, Kenya \\ ${ }^{5}$ Department of Periodontology, University of Nairobi, Nairobi, Kenya \\ Email: ${ }^{*}$ fawzia_butt@yahoo.co.uk
}

Received 19 January 2012; revised 20 February 2012; accepted 1 March 2012

\begin{abstract}
Background: The diversity of benign jaw tumours may cause difficulty in a correct diagnosis and institution of an appropriate treatment. Data on the prevalence of these tumours is scarce from the African continent. We present a 19-year audit of benign jaw tumours and tumour-like lesions at a University teaching hospital in Nairobi, Kenya. Methods: Histopathological records were retrieved and re-examined from the Department of Oral and Maxillofacial pathology, University of Nairobi from 1992 to 2011. The jaw tumours were classified according to the latest WHO classification. Results: During the 19-year audit, 4257 biopsies were processed of which 597 (14.02\%) were jaw tumours within an age range of between 4 to 86 years. There was greater number of odontogenic tumours $417(69.85 \%)$ than the bone related lesions $180(30.15 \%)$. Of the odontogenic tumours, the epithetlial and in the bone related types, the fibro-osseous lesions were frequent. Conclusion: Ameloblastoma and ossifying fibroma were the most frequent tumours reported in this audit. The information regarding the prevalence of these tumours is scarce from the continent and can be useful in early detection and management before they cause facial deformity.
\end{abstract}

Keywords: Benign Jaw Tumours; Odontogenic Tumours; Bone Related Lesions

\section{INTRODUCTION}

The importance of oral and maxillofacial tumours lies in the fact that they are rare, cause disfiguring of the face necessitating subsequent reconstructive surgery [1]. The

"Corresponding author. skull, jaws and facial bones are not only the site of a number of unusual lesions but, also pose unique histological problems often associated with intra-oral variation in oral structure ranging from potentially malignant to pseudo-malignant features [2,3]. Odontogenic tumours (OT) are exclusive to the jaws, as they are derived from epithelial and mesenchymal elements that are part of the tooth forming apparatus. There is a variance in the frequency of the various types of OT geographically [4-6]. They account for between $1 \%$ to $30 \%$ of oral lesions [7-9]. While there have been various studies done in some countries across the continents including Africa, there remain unanswered questions as to the frequency and incidence of some OT. [10,11]. Bone related lesions (BRL) include the fibro-osseous lesions (FOLs) in addition to cherubism and aneurysmal bone cysts $(\mathrm{ABC})$ in accordance with the latest classification [12]. The WHO classifies the following as FOL among the non-odontogenic tumours (NOT): fibrous dysplasia (FD), Ossifying fibroma (OF) and cementosseous dysplasia (COD) [13]. FOLs are a group of poorly defined lesions with more than $70 \%$ affecting the head and neck region [14]. Wakiaga et al. in 1997 have documented a Kenyan series while, Kamulega and Boniface in 2008 presented a combined series in from Tanzania and Uganda $[15,16]$.

The purpose of the present study was to conduct a 19-year audit of benign tumours of the jaws diagnosed at a teaching University teaching hospital in Kenya.

\section{MATERIAL AND METHOD}

Study Site: The University of Nairobi Dental Hospital (UNDH), Oral Pathology Laboratory which is the main national referral centre for specialized diagnosis of Oral and Maxillofacial pathology.

Method: The histopathology register and filed reports were mainly accessed to extract case information in- 
cluding age at initial presentation, gender, site of lesion where specified and the histopathological diagnosis. The case definition in this study was any benign tumour/tumour-like lesion diagnosed for the first time in this centre. Recurrent tumours and tumour-like lesions with a previously diagnosed primary site were excluded. Benign tumours were coded according to the WHO classification [12]. Since, throughout the years, many of the cases presented late with extensive lesions it was difficult to delineate the exact site of affliction by some these lesions. Parameters of interest were analysed with SPSS version 12.0.1.

\section{RESULTS}

During the 19-year-period there were 4257 biopsies processed among which 597 (14.02\%) were diagnosed as tumours of the jaw bones with an equal gender predilection. There was a greater number of OT $417(69.85 \%)$ than BRLs 180 (30.15\%). The M: F ratio of OT was 1:1 while, that of the BRL $1: 1.6$. The age range of cases was from $4-86$ years $($ mean $=25.4$ yrs $)$, with the majority (76.5\%) having been between 10 to 39 years of age. There were remarkably very few patients presenting with these lesions below the age of 9 and above the age of 70 years (Figure 1).

\subsection{Odontogenic Tumours}

The age range of the OT was between 5 - 85 years (mean $=24.1$ ) with equal gender distribution. The most commonly affected age was between 11 - 50 years, and surprising with hardly any patients in the less than 10 and above the 50 year age group (Figure 2). Among the OTs those arising from the epithelial (58\%) component were the most common whilst those from the mesoderm and mixed type consisted of only $6 \%$. The ameloblastoma was the most frequent epithelial OT (45.9\%), followed by the keratocystic odontogenic tumour (KCOT) at $11.2 \%$. Other tumours included $0.8 \%$ calcifying epithelial odontogenic tumour (CEOT) and $0.2 \%$ adenomatoid odontogenic tumour (AOT). There were two types mesodermal OTs recorded: the myxoma (4.9\%) presenting at an average age of 25.6 yrs and the cementoma $(1.2 \%)$ at 47.1 yrs. The mixed OTs had the lowest of frequency of between $0.2 \%-2.7 \%$ (Table 1 ).

\subsection{Bone Related Lesions}

This group consisted of OF (62.8\%), FD (21.7\%), COD $(10 \%)$, giant cell granuloma (GCG-2.8\%) and aneurysmal bone cyst (ABC-2.8\%). The FOLs represented $2.47 \%$ of the total biopsy specimens. Remarkably, there were more females (110) than males (70) cases with ages ranging from 4 - 86 years (Figure 3 ). The gender preva-
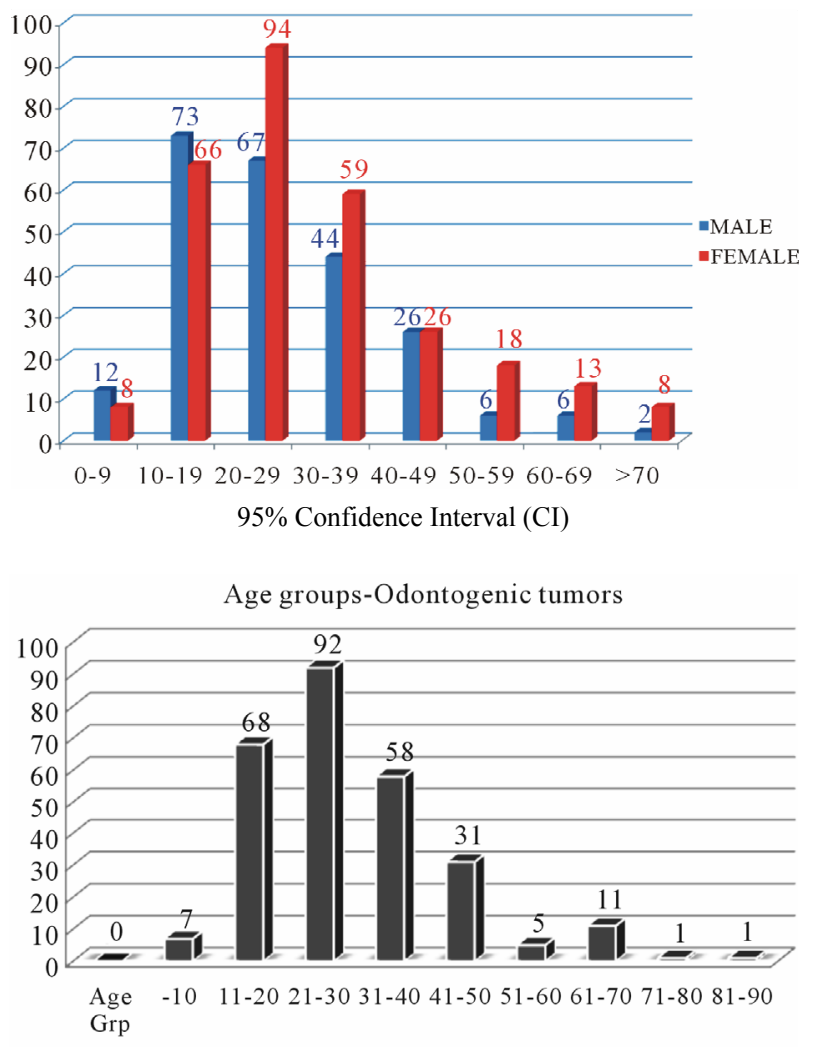

Figure 1. Gender and age distribution.

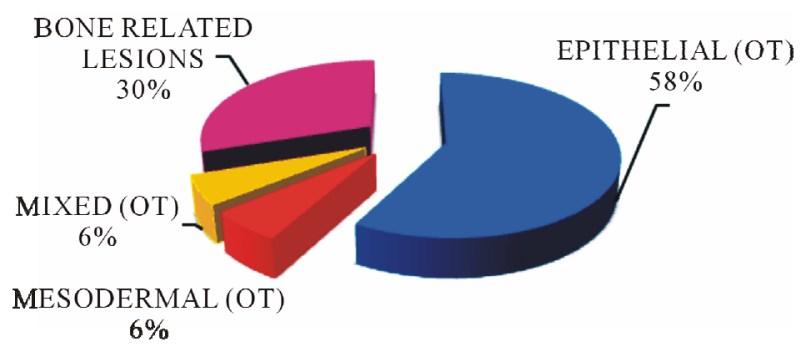

Figure 2. Proportion of odontogenic (OT) and bone related lesions (BRL).

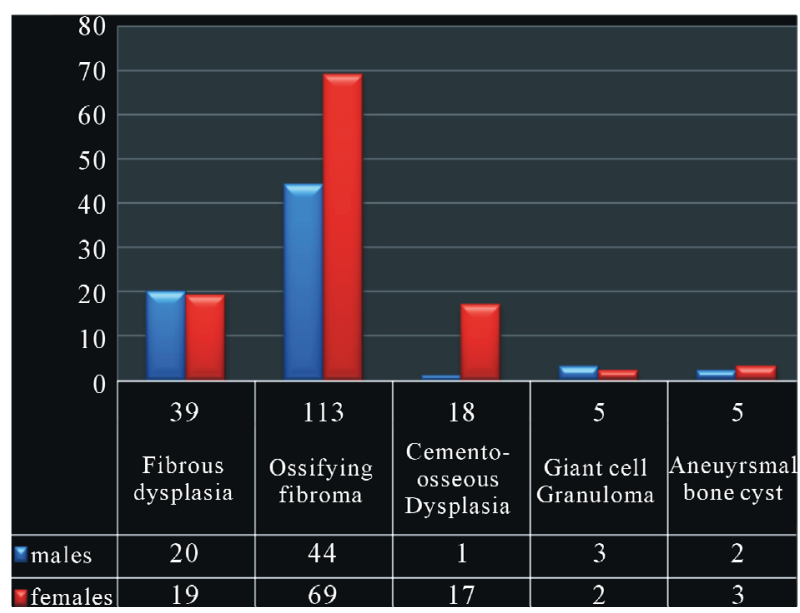

Figure 3. Shows the gender distribution and frequency BRLs. 
lence was equal in $\mathrm{FD}$, with female predominance noted in both COD and OF. The mean age (51.9 yrs) of those with COD was much higher than the rest of the BRL while that of the $\mathrm{ABC}$ was the lowest 21.6yrs. Both FD and OSF presented over a wide age range ( $4-72 \mathrm{yrs})$ compared to other BRLs (Table 2).

\section{DISCUSSION}

\subsection{Odontogenic Tumours}

OT have a specific histological structure reflecting various stages of odontogenesis and are located mainly in the jaws, they are however infrequent in gnathic bones and must be considered in the differential diagnosis of bony lesions in the jaws $[16,17]$. The reported relative frequency of OT is generally low: India (4.13\%), Asia (2.14\%), S. America (1.82\%), N America (1.55\%) Euro- pean $(0.74 \%)$, the highest values being in Africa (Nigeria) $(9.6 \%-19 \%)$. Not surprisingly, a value of $14.2 \%$ for this study is well within the high range. Clearly there is variation seen in the geographically distribution of OT [4, $9,15,18-22]$. OT were most frequent in the $1^{\text {st }}$ to the $4^{\text {th }}$ decade in this study which is almost similar to previous reports $[8,15,23]$. Female preponderance has been seen in Michigan and in Hongkong while males were more in China, Brazil and Nigeria [15,20,24,25]. However, there was equal gender distribution in this group as also documented by others [8,9,26-28].

Ameloblastoma was the most common OT which is in agreement with other reports from Africa, Hong Kong, China, Jamaica, Brazil, Turkey and India [10,11, 14,15,18,27,29-33]. This is in contrast to studies from US, Canada, Mexico, Chile, Jordan and Estonia where odontoma is the most prevalent [19,20,22,26,34-37].

Table 1. Illustrates the frequency, age range/mean and gender distribution of the OT.

\begin{tabular}{|c|c|c|c|c|c|c|}
\hline $\begin{array}{c}\text { TUMOURS } \\
\text { EPITHELIAL }\end{array}$ & FREQUENCY & $\begin{array}{c}\text { PERCENTAGE } \\
\%\end{array}$ & MALE & FEMALE & $\begin{array}{c}\text { AGE RANGE } \\
\text { (yrs) }\end{array}$ & MEAN (yrs) \\
\hline Ameloblastoma & 274 & 45.90 & 137 & 137 & $5-85$ & 29.7 \\
\hline KCOT & 67 & 11.20 & 33 & 34 & $10-62$ & 25.8 \\
\hline CEOC & 5 & 0.80 & 2 & 3 & $12-32$ & 18.6 \\
\hline AOT & 1 & 0.20 & 0 & 1 & 17 & 17 \\
\hline TOTAL & 347 & 58.10 & 172 & 175 & & \\
\hline \multicolumn{7}{|l|}{ MESODERMAL } \\
\hline Myxoma & 29 & 4.90 & 9 & 20 & $8-60$ & 25.6 \\
\hline Cementoma & 7 & 1.20 & 1 & 6 & $11-68$ & 47.1 \\
\hline TOTAL & 36 & 6.00 & 10 & 26 & & \\
\hline \multicolumn{7}{|l|}{ MIXED } \\
\hline Odontoma & 16 & 2.70 & 8 & 8 & $7-30$ & 16.5 \\
\hline Ameloblastic Fibroma & 7 & 1.20 & 4 & 3 & $11-32$ & 19.7 \\
\hline Myxofibroma & 6 & 1 & 3 & 3 & $1-33$ & 22.8 \\
\hline $\mathrm{CCOT}$ & 4 & 1 & 0 & 4 & $14-48$ & 25.8 \\
\hline Amelofibro-odontoma & 1 & 0.20 & 1 & 0 & 16 & 16 \\
\hline TOTAL & 34 & 5.70 & 16 & 18 & & \\
\hline
\end{tabular}

Table 2. Show the age range, mean and standard deviation of BRLs.

\begin{tabular}{cccccc}
\hline Tumour type & Frequency & $\%$ & Age range (yrs) & Mean age & Std dev $+/-$ \\
\hline FD & 39 & 21.7 & $4-72$ & 23.4 & 13.8 \\
OSF & 113 & 62.8 & $4-72$ & 27.0 & 13.7 \\
COD & 18 & 10 & $30-86$ & 51.9 & 16.0 \\
GCG & 5 & 2.8 & $7-35$ & 18.2 & 10.4 \\
ABC & 5 & 2.8 & $11-40$ & 21.6 & 9.21 \\
\hline
\end{tabular}


Simon et al. had equal gender distribution, similar to our finding while, some had a male prevalence and others a female $[7,8,10,15,26,28,32,33,38,39]$. Ameloblastoma presents more in the $3^{\text {rd }}-5^{\text {th }}$ decades of life with a peak incidence in the $3^{\text {rd }}$ decade: Mullapudi documented a younger age group which was similar to Reichart who stated that ameloblastoma occur in a younger age group in the developing countries [12,33]. The mean and age range was the same as in some reports, although higher than documented by Stypulkowska and Parkin et al. [10, $15,16,29,33,40]$. The greater percentage of ameloblastoma could be due to to referral patterns and late presentation in Africa $[8,41]$. It is not surprising that Sweden reports an incidence as low as 0.3 per million per year [42].

The second most common tumour in this study was KCOT followed by myxoma, which is different from the findings of Simon et al. who reported the myxoma as the most prevalent after ameloblastoma [10]. The gender distribution was equal although Stoelinga reported a male predominance [43]. The WHO has recently classified calcifying odontogenic cyst (COC) a benign cystic neoplasm of odontogenic origin, similarly, the odontogenic keratocyst has been redesignated as KCOT due to the aggressive behaviour, histology and genetics $[44,45]$. KCOT has been known to occur in patients over a wide age range of between 7 to 93 years with a peak in the third decade [46]. Our age range comparatively was narrower and the mean a decade younger.

Myxoma was the third most common in this population representing a $4.90 \%$ of the OT. When the 1992 classification was used, this lesion accounted for $8 \%$ of all OTs in a study done by Avelar et al., to determine the world incidence of OT and this was in agreement with several studies showing a wide variation in the prevalence of this tumour $(4.7 \%$ to $17.7 \%)$ [8,20,25,31,35]. It shows a lower distribution in Asia with a higher trend in America, Africa and Europe [15,18,34]. There were almost twice as many females as males similar to other reports from Nigeria, Brazil, Turkey and Chile [19, $21,25,31]$. It typically occurs between the $2^{\text {nd }}$ and $4^{\text {th }}$ decades, however, there was a wider age range in this series although the mean age was 25.6 yrs $[47,48]$.

Odontoma, a hamartomatous malformation was the next common with an equal gender distribution this was in contrast to observation by others who had a slight male predominance $[4,22,34,31]$. They are usually diagnosed in the second decade of life, the average age in this series was 16.5 years. They have been reported as the commonest lesions by Scholl et al. Buchner et al. and Mosqueda-Taylor et al. which is in contrast to our results $[34,36,48]$. Odontoma is a rare lesion in the Africa region, probably because it is asymptomatic and patients rarely seek medical treatment. It is most likely for the ones that are excised would not be sent for histopathology (due to cost) which may explain the reason for the under reporting.

The AOT is more common in females than males $(1.9: 1)$. It represents approximately $3 \%$ of OT and appears between the ages of 5 and 30 years. Pogrel and Schmidt 2006 and Ladeinde et al. found AOT as second most frequent OT after ameloblastoma in contrast to other studies in Africa. [8,9,25,49]. There was only one female in this series with AOT. Simon et al., who reported very low frequency $(0.9 \%-2.6 \%)$ of odontoma, CEOT, cementoblastoma, ameloblastic fibroma, COC and AOT [10]. Ladeinde too reported low frequency of CEOT, exclusive to females, confirming the rarity of these tumours $[15,19,36]$. In our population the number of patients with AOT, CEOC, myxofibroma, CCOT and amelofibrodontoma were few.

\subsection{Bone Related Lesions}

The epidemiology of OF and COD is unclear due to the confusion between the two lesions. OF is known to occur over a wide age range, it presents mostly in $3^{\text {rd }}$ and $4^{\text {th }}$ decades of life, with a female predilection. There were more females in our series and our age followed the same pattern. OF are believed to be confined to the jaws and craniofacial complex [50,51].

In our study the most common FOL was OF, FD followed by COD. FD of the monostotic type is most common accounting for up to $80 \%-85 \%$ of all cases with the jaws being the most commonly affected sites. It is mostly diagnosed during the $2^{\text {nd }}$ decade of life with an equal M:F predilection [51]. There was equal gender distribution, although the age range was wide the mean was in the second decade as in the previous report. [49]. COD occurs in tooth bearing areas of the jaws and is probably the most common FOL encountered in clinical practise. The fewer cases of COD in this data could be due to their asymptomatic nature, they are an incidental finding and rarely subject to a biopsy. It is predominant in the $4^{\text {th }}$ to $5^{\text {th }}$ decade, there was only one male diagnosed with COD the rest were females presenting at an average age in the $5^{\text {th }}$ decade [52].

GCG of the jaws are most often found in children and young adults, with up to $75 \%$ of cases occurring before 30 years of age. Females are affected twice as frequently as males. ABCs of the jaws are uncommon and the mean age of presentation is 20 yrs with a female predilection, this was identical to our data [49]. The majority (60\%) of GCG of the jaws occur before the age of $30 \mathrm{yrs}$, its presentation in this study had a mean age of 21.6yrs and a limited age range unlike that reported [51]. The number of cases of both GCG and $\mathrm{ABC}$ are too few to make any comparisons, although the $\mathrm{M}: \mathrm{F} \approx 1$, the patients pre- 
sented below the age of 40 years and mean age was similar that reported.

\section{REFERENCES}

[1] Nzegwu, M.A., Uguru, C., Okafor, O.C., Ifeoma, O. and Olusina, D. (2008) Pattern of oral and jaw tumours seen in eastern Nigeria. European Journal of Cancer Care, 17, 532-534.

[2] Odell, E.W. (2001) Bony lesions of the jaws and facial bones. CPD Cellular Pathology, 3, 28-32.

[3] Barret, A.W. and Speight, P.M. (2001) Diagnostic problems in oral mucosal pathology and how to approach them. CPD Cellular Pathology, 3, 17-21.

[4] Gupta, B. and Ponniah, I. (2010) The pattern of odontogenic tumors in a government teaching hospital in the southern Indian state of Tamil Nadu. Oral Surgery, Oral Medicine, Oral Pathology, Oral Radiology, and Endodontology, 110, e32-e39. doi:10.1016/j.tripleo.2010.02.035

[5] Regezi, J.A. and Scuibba, J. (1993) Oral pathology: Clinic-pathologic correlations. WB Saunders, Philadelphia.

[6] Barnes, L., Eveson, J., Reichart, P., Sidransky, D. and World Health Organization classification of tumours. (2005) Pathology and genetics of head and neck tumours. IARC Press, Lyon.

[7] Ulmansky, M., Lustmann, J. and Balkin, N. (1999) Tumours and tumour-like lesions of the oral cavity and related structures in Israeli children. International Journal of Oral and Maxillofacial Surgery, 28, 291-294. doi:10.1016/S0901-5027(99)80161-1

[8] Arotiba, J.T., Ogunbiyi, J.O. and Obiechina, A.E. (1997) Odontogenic tumours: A 15-year review from Ibadan, Nigeria. British Journal of Oral and Maxillofacial Surgery, 35, 363-367. doi:10.1016/S0266-4356(97)90411-3

[9] Odukoya, O.O. (1995) Odontogenic tumours: Analysis of 289 Nigerian cases. Journal of Oral Pathology \& Medicine, 24, 454-457.

doi:10.1111/j.1600-0714.1995.tb01133.x

[10] Simon, E.N., Merkx, M.A., Vuhahula, E., Ngassapa, D. and Stoelinga, P.J. (2005) A 4-year prospective study on epidemiology and clinicopathological presentation of odontogenic tumors in Tanzania. Oral Surgery, Oral Medicine, Oral Pathology, Oral Radiology, and Endodontology, 99, 598-602. doi:10.1016/j.tripleo.2004.10.004

[11] Kamulega, A. and Kalyanyama, B.M. (2008) Oral maxillofacial neoplasms in an East African population a 10 year retrospective study of 1863 cases using histopathological reports. BMC Oral Health, 8, 19. doi:10.1186/1472-6831-8-19

[12] Reichart, P.A., Philipsen, H.P. and Sciubba, J. (2006) The new WHO classification of tumours of the head and neck. What has changed? Mund Kiefer Gesichtschir, 1, 1-2. doi:10.1007/s10006-005-0653-1

[13] Liu, Y., Wang, H., You, M., Yang, Z., Miao, J., Shimizutani, K., et al. (2010) Ossifying fibromas of the jaw bone: 20 cases. Dentomaxillofacial Radiology, 39, 57-63.

\section{doi:10.1259/dmfr/96330046}

[14] Wakiaga, J.M., Onyango, J.F. and Awange, D.O. (1997) Clinico-pathological analysis of jaw tumours and tumour-like conditions at the Kenyatta National Hospital. East African Medical Journal, 74, 65-68.

[15] Ladeinde, A.L., Ajayi, O.F., Ogunlewe, M.O., Adeyemo, W.L., Arotiba, G.T., Bamgbose, B.O., et al. (2005) Odontogenic tumours: A review of 319 cases in a Nigerian teaching hospital. Oral Surgery, Oral Medicine, Oral Pathology, Oral Radiology, and Endodontology, 99, 191-195. doi:10.1016/j.tripleo.2004.08.031

[16] Stypulkowska, J. (1998) Odontogenic tumours and neoplastic-like changes of the jaw bones. Clinical study and evaluation of treatment results. Folia Medica Cracoviensia, 39, 35-141.

[17] Antunes, A.A., Silva, J.L., Silva, P.V. and Antunes, A.P. (2006) Tumores odontogênicos: Análise de 128 casos. Revista Brasileira de Cirurgia de Cabeça e Pescoço, 35, 160-163.

[18] Luo, H.Y. and Li, T.-J. (2009) Odontogenic tumours: A study of 1309 cases in a Chinese population. Oral Oncology, 45, 706-711. doi:10.1016/j.oraloncology.2008.11.001

[19] Ochsensius, G., Ortega, A., Godoy, L., Penaflel, C. and Escobar, E. (2002) Odontogenic tumours in Chile: A study of 362 cases. Journal of Oral Pathology \& Medicine, 31, 415-420. doi:10.1034/j.1600-0714.2002.00073.x

[20] Avelar, R.L., Antunes, A.A., De Santana Santos, T., et al. (2008) Odontogenic tumours: Clinical and pathology study of 238 cases. Brazilian Journal of Otorhinolaryngology, 74, 668-673.

[21] Olgac, V., Koseoglu, B.G. and Aksakalli, N. (2006) Odontogenic tumours in Istanbul: 527 cases. British Journal of Oral and Maxillofacial Surgery, 44, 386-388. doi:10.1016/j.bjoms.2005.07.002

[22] Tamme, T., Soots, M., Kulla, A., et al. (2004) Odontogenic tumours, a collaborative retrospective study of 75 cases covering more than 25 years from Estonia. Journal of Cranio-Maxillofacial Surgery, 32, 161-165. doi:10.1016/i.jems.2003.12.004

[23] Lu, Y., Xuan, M., Takata, T., Wang, C., He, Z., Zhou, Z., et al. (1998) Odontogenic tumours: A demographic study of 759 cases in Chinese population. Oral Surgery, Oral Medicine, Oral Pathology, Oral Radiology, and Endodontology, 86, 707-714. doi:10.1016/S1079-2104(98)90208-6

[24] Luo, H.Y. and Li, T.J. (2009) Odontogenic tumours: A study of 1309 cases in a Chinese population. Oral Oncology, 45, 706-711. doi:10.1016/j.oraloncology.2008.11.001

[25] Adebayo, E.T., Ajike, S.O. and Adekeye, E.O. (2005) A review of 318 odontogenic tumours in Kaduna, Nigeria. Journal of Oral and Maxillofacial Surgery, 63, 811-819. doi:10.1016/i.joms.2004.03.022

[26] Regezi, J.A., Kerr, D.A. and Courtney, R.M. (1978) Odontogenic tumours: Analysis of 706 cases. Journal of Oral Surgery, 36, 771-778.

[27] Wu, P.C. and Chan, K.W. (1985) A survey of tumours in 
Hong Kong Chinese. British Journal of Oral and Maxillofacial Surgery, 23, 92-103. doi:10.1016/0266-4356(85)90058-0

[28] Mosadomi, A. (1975) Odontogenic tumours in African population: Analysis of twenty-nine cases seen over a 5-period. Oral Surgery, Oral Medicine, Oral Pathology, 40, 502-521. doi:10.1016/0030-4220(75)90248-0

[29] Chidzonga, M.M., Lopez, V.M. and Portilla Alvarez, A.L. (1996) Orofacial biopsies a survey of 1732 cases seen over a 10 year period. Central African Journal of Medicine, 42, 102-108.

[30] Ogunsalu, C.O. (2003) Odontogenic tumours from two canters in Jamaica: A 15-year review. West Indian Medical Journal, 52, 285-289.

[31] Fernandes, A.M., Duarte, E.C., Pimenta, F.J., Souza, L.N., Santos, V.R., Mesquita, R.A., et al. (2005) Odontogenic tumours: A study of 340 cases in a Brazilian population. Journal of Oral Pathology \& Medicine, 34, 583-587. doi:10.1111/j.1600-0714.2005.00357.x

[32] Gunham, O., Erseven, G., Ruacan, S., Celasun, B., Ayidutan, Y., Ergun, E., et al. (1990) Odontogenic tumours: A series of 409 cases. Australian Dental Journal, 35, 518-522. doi:10.1111/j.1834-7819.1990.tb04683.x

[33] Mullapudi, S.V., Putcha, U.K. and Boindala, S. (2011) Odontogenic tumours and giant cell lesions of jaws-A nine year study. World Journal of Surgical Oncology, 9, 68. doi:10.1186/1477-7819-9-68

[34] Buchner, A., Merrell, P.W. and Carpenter, W.M. (2006) Relative frequency of central odontogenic tumours: A study of 1,088 cases from Northern California and comparison to studies from other parts of the world. Journal of Oral and Maxillofacial Surgery, 64, 1343-1352. doi:10.1016/j.joms.2006.05.019

[35] Daley, T.D., Wysocki, G.P. and Pringle, G.A. (1994) Relative incidence of odontogenic tumours and oral and jaw cysts in a Canadian population. Oral Surgery, Oral Medicine, Oral Pathology, 77, 276-280. doi:10.1016/0030-4220(94)90299-2

[36] Mosqueda-Taylor, A., Ledesma-Montes, C., CaballeroSandoval, S., Portilla-Robertson, J., Ruiz-Godoy Rivera, L.M., Meneses-Garcia, A. (1997) Odontogenic tumours in Mexico: A collaborative retrospective study. Oral Surgery, Oral Medicine, Oral Pathology, Oral Radiology, and Endodontology, 84, 672-675. doi:10.1016/S1079-2104(97)90371-1

[37] Al-Khateeb, T., Hamasha, A.A. and Almasri, N.M. (2003) Oral and Maxillofacial tumours in North Jordanian children and adolescents: A retrospective analysis over 10 years. International Journal of Oral and Maxillofacial Surgery, 32, 78-83. doi:10.1054/ijom.2002.0309

[38] Adebayo, E.T., Ajike, S.O. and Adekeye, E.O. (2002) Odontogenic tumours in children and adolescent: A study of 78 Nigerian cases. Journal of Cranio-Maxillofacial Surgery-Guide for Authors, 30, 267-272.

[39] Mehlissch, D.R., Dahlin, D.C. and Masson, J.K. (1972) Ameloblastoma: A clinicopathologic report. Journal of Oral Surgery, 30, 9-22.
[40] Parkin, G.E., Armah, G.A. and Ampofo, P. (2007) Tumours and tumour-like lesions of the lower face at Korle $\mathrm{Bu}$ teaching hospital, Ghana-An eight year study. World Journal of Surgical Oncology, 5, 48.

[41] Fregnani, E.R., Fillipi, R.Z., Oliveiria, C.R., Vargas, P.A. and Almeida, O.P. (2002) Odontomas and ameloblastomas: Variable prevalences around the world? Oral Oncology, 38, 807-808. doi:10.1016/S1368-8375(02)00050-7

[42] Larsson, A. and Almeren, H. (1978) Ameloblastoma of the jaws, an analysis of consecutive series of all cases reported to the Swedish cancer registry during 1958-1971. Acta Pathologica et Microbiologica Scandinavica, 86, 337.

[43] Stoelinga, P.J.W. (2001) Longterm follow-up on keratocysts treated according to a defined protocol. International Journal of Oral and Maxillofacial Surgery, 30, 14-25. doi:10.1054/ijom.2000.0027

[44] Praetorius, F., Ledesma-Montes, C., Barnes, L., Eveson, J.W., Reichart, P. and Sidransky, D. (2005) Calcifying cyst odontogenic tumour. In World Health Organization classification of tumours: Pathology and genetics of head and neck classification of tumours: Pathology and genetics of head and neck tumours. IARC Press, Lyon.

[45] Madras, J. and Lapointe, H. (2008) Keratocystic Odontogenic tumour: Reclassification of the odontogenic keratocyst from cyst to tumour. Journal of the Canadian Dental Association, 74. 165-165.

[46] Stoelinga, P.J.W. and Peters, J.H. (1973) A note on the origin of keratocysts of the jaws. International Journal of Oral Surgery, 2, 37-44. doi:10.1016/S0300-9785(73)80001-8

[47] Kaffe, I., Naor, H. and Buchner, A. (1997) Clinical and radiological features of odontogenic myxoma of the jaws. Dentomaxillofac Radiol, 26, 299-303. doi:10.1038/sj.dmfr.4600261

[48] Scholl, R.J., Kellet, H.M., Neumann, D.P. and Lurie A.G. (1999) Cysts and cystic lesions of the mandible: Clinical and radiologic-histopathologic review radiographics. The Journal of Continuing Medical Eduation in Radiology, 19, 1107-1124.

[49] Pogrel, M.A., Schimdt, B.L. and G. Robertson, C. (2006) Odontogenic and nonodontogenic tumours of the jaws. Clinical Pathology, Chapter 23, 497-498.

[50] Fletcher, C.D.M., Unni, K.K. and Mertens, F. (2002) World Health Organization classification of tumors: Pathology and genetics of soft tissue and bone. IARC Press, Lyon.

[51] Neville, B.D., Damm, D.D., Allen, C.M., et al. (2002) Oral and Maxillofacial Pathology. 2nd Edition, W.B. Saunders Company, Philadelphia.

[52] Su, L., Weathers, D.R. and Waldron, C.A. (1997) Distinguishing features of focal cemento-osseous dysplasia and cemento-ossifying fibromas: II. A clinical and radiologic spectrum of 316 cases. Oral Surgery, Oral Medicine, Oral Pathology, Oral Radiology, and Endodontology, 84, 540-549. doi:10.1016/S1079-2104(97)90271-7 